\title{
CORPO, EDUCAÇÃO FÍSICA E ESPORTE: ESTUDOS FRANCESES E BRASILEIROS NO PERÍODO DE 1970-1990
}

\author{
THE BODY, PHYSICAL EDUCATION AND SPORTS: FRENCH AND BRAZILIAN \\ STUDIES IN 1970-1990
}

CUERPO, EDUCACIÓN FÍSICA Y DEPORTE: ESTUDIOS FRANCESES Y
BRASILEÑOS EN EL PERIODO 1970-1990

Terezinha Petrucia da Nóbrega*, Bernard Andrieu**

Palavras chave: Corpo humano. Conhecimento. Educação Física. Esportes.

Keywords: Human body. Knowledge. Physical Education. Sports.

Palabras clave: Cuerpo humano. Conocimiento. Educación Física. Deportes.
Resumo: Este ensaio visa refletir sobre os estudos da filosofia e da história do corpo no Brasil e na França, no período de 1970-1990, considerando dados advindos de teses e publicações de alguns pioneiros no campo da Educação Física e Ciências das Atividades Físicas e Esportivas (STAPS). Assim, discutimos o cenário da produção de conhecimento em torno do corpo sob o prisma de duas disciplinas que se comunicam: a História e a Filosofia, e que vão influenciar os estudos, as pesquisas, a formação acadêmica e profissional na área da Educação Física em ambos os países.

Abstract: This essay aims to reflect on studies on body philosophy and history in Brazil and France in 1970-1990, considering data from thesis and publications by some pioneers in the field of Physical Education and STAPS. We discuss the scenario of the production of knowledge on the body from the perspective of two disciplines that communicate mutually - History and Philosophy - and that influenced studies, research, academic and professional training in the area of Physical Education in both the countries.

Resumen: Este ensayo tiene como objetivo reflexionar sobre los estudios de la filosofía y la historia del cuerpo en Brasil y en Francia en el período 1970-1990, teniendo en cuenta datos procedentes de tesis y publicaciones de algunos pioneros en el campo de la Educación Física y Ciencias de las Actividades Físicas y Deportivas (STAPS). Así, discutimos el escenario de la producción de conocimiento acerca del cuerpo desde el prisma de dos disciplinas que se comunican - la historia y la filosofía - y que tendrán influencia en los estudios, la investigación, la formación académica y profesional en el campo de la Educación Física en ambos países.
*Universidade Federal do Rio Grande do Norte. Natal, RN, Brasil. E-mail: pnobrega68@gmail.com

**Universidade Paris Descartes, Paris, França.

E-mail: bernard.andrieu@ parisdescartes.fr

Recebido em: 22-07-2017 Aprovado em: 13-12-2017

DOI: http://dx.doi.org/10.22456/1982-8918.75177 (c) (1) 은 Licence 


\section{INTRODUÇÃOO}

Na França, os estudos de Andrieu (1993; 2005) mostram a pesquisa do corpo, notadamente no domínio das Ciências Sociais e Humanas e sua influência na Educação Física ou Ciências das Atividades Físicas e esportivas (STAPS). No Brasil, os estudos de Almeida, Bracht e Ghidetti (2013) e de Nóbrega et al. (2003) também buscam situar esse aspecto epistemológico. Outros estudos mostram as influências entre a Europa e 0 Brasil, tais como Nóbrega, Mendes e Gleyse (2016); Mendes e Gleyse (2015); Gleyse, Soares e Dalben (2014); Gleyse e Soares (2008; 2012). Esses são apenas alguns exemplos que remetem ao escopo deste ensaio sobre os estudos do corpo na França e no Brasil. Ao ler o conjunto desses trabalhos, destacamos as relações entre a filosofia e a história do corpo como expressão epistemológica no domínio da Educação Física.

Apresentamos uma visão panorâmica e não exaustiva, em que destacamos alguns dos fundadores e pioneiros da Educação Física e STAPS em termos de estudos históricos e filosóficos sobre o corpo. Vindos do campo da Educação Física, da História ou da Filosofia, eles apresentam horizontes epistemológicos para refletir e compreender as práticas corporais, a cultura corporal, a cultura de movimento, o esporte, o lazer. A abordagem metodológica da pesquisa caracteriza-se pela apropriação fenomenológica, centrada nos elementos da intencionalidade na escolha das fontes analisadas e da redução fenomenológica como campo criador de sentidos epistemológicos, científicos, históricos, entre outros (MERLEAU-PONTY, 1945).

Trata-se de uma análise documental, cujas fontes encontram-se em teses, correspondências e entrevistas de autores franceses, André Rauch e Georges Vigarello; e dos brasileiros Silvino Santin e Carmen Lucia Soares. A escolha desses autores deu-se de forma intencional, considerando-se os trabalhos pioneiros que realizaram no campo da Educação Física a partir dos referenciais epistemológicos advindos dos campos da História e da Filosofia, cuja repercussão é significativa em ambos os países. Tendo em vista o escopo deste artigo não temos condições de abordar as produções de outros pioneiros em torno das questões do corpo, das práticas corporais e da cultura de movimento, o que colocamos como perspectiva de outros estudos e publicações. Nesses estudos, particularmente os que se apoiam em Michel Foucault e em Merleau-Ponty, os domínios da Filosofia e da História se comunicam. 0 trabalho pioneiro publicado nos três volumes da História do corpo na França em 2006 e, dois anos depois, no Brasil (COURTINE; CORBIN; VIGARELLO, 2006), mostrará as influências recíprocas que tocam a filosofia e a história do corpo. A partir dessas referências, interroga-se como o corpo torna-se um objeto de pesquisa histórica e filosófica. Trata-se, segundo Courtine (2006), de uma interrogação cada vez mais legítima, pois em uma tradição filosófica dominada pelo cartesianismo o corpo foi visto como um objeto secundário até pelo menos o fim do século XIX.

Courtine (2006) recorre às ideias de Merleau-Ponty para afirmar que, diferentemente do século XIX, o século XX apagou a linha divisória e vê a vida humana como espiritual e corporal de parte a parte, apoiando-se sempre no corpo. "O século XX restaurou e aprofundou a questão da carne, ou seja, do corpo animado" (MERLEAU-PONTY apud COURTINE, 2006, p. 7). ${ }^{1}$ Não se trata, portanto, do corpo visto como um feixe de músculos e seu funcionamento mecânico puramente, mas o corpo atravessado pela linguagem, pelo desejo e pela história.

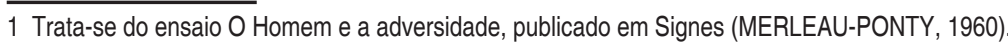


De forma panorâmica e transversal, abordamos essa história das ideias do corpo no cenário da Educação Física no Brasil e das Ciências das Atividades Físicas e esportivas (STAPS) na França, buscando as vias de comunicação, influências e perspectivas de diálogos entre estudos filosóficos e históricos sobre o corpo. Essa compreensão das relações entre História e Filosofia foi recentemente abordada por Revel (2015). A autora nos fornece uma leitura da paisagem teórica a respeito das compreensões de história e política na França após 1945, sob a luz das filosofias de Maurice Merleau-Ponty e Michel Foucault. Tal perspectiva coaduna com a intenção deste ensaio, posto que possibilita perceber as aproximações, os diálogos e a abertura criada para o pensamento que se produz nos campos da História e da Filosofia, notadamente no que concerne às questões da subjetividade e do corpo.

Para Foucault (1992) o desenvolvimento das Ciências Humanas convida-nos mais ao desaparecimento do que a uma apoteose do homem. Segundo o autor, temos um sistema de pensamento nas Ciências Humanas, falta o diagnóstico dos modos de ser, de como foi possível se passar do louco à doença mental, dos suplícios à pena e ao regime penitenciário, por exemplo. Nesse contexto, o saber muda de forma e de natureza, retificam-se métodos, racionalizam-se seus conceitos, configuram-se objetos. A representação passa à ordem do dia e as Ciências Humanas se configurarão como sendo aquelas que tentarão situar o sujeito da representação. $O$ homem, para as ciências do homem, "[...] constitui representações graças às quais ele vive e a partir das quais detém essa estranha capacidade de poder se representar justamente a vida" (FOUCAULT, 1992, p. 369). Destacamos aqui a emblemática passagem dessa obra que atesta a efemeridade de nossas representações:

\begin{abstract}
O homem é uma invenção cuja recente data a arqueologia de nosso pensamento mostra facilmente. E talvez o fim próximo. Se talvez estas disposições viessem a desaparecer tal como apareceram se, por algum acontecimento de que podemos quanto muito pressentir a possibilidade, mas de que no momento não conhecemos ainda nem a forma nem a promessa, se desvanecessem, como aconteceu na curva do século XVIII, com o solo do pensamento clássico - então se pode apostar que o homem se desvaneceria, como, na orla do mar, um rosto de areia (FOUCAULT, 1992, p. 404).
\end{abstract}

Conforme Dosse (2007), é manifestamente a morte do homem que fascina a época, e numerosos são aqueles que se comprimem atrás do cortejo fúnebre. As negações sucessivas do sujeito na linguística saussuriana, na antropologia estrutural e na psicanálise lacaniana acabam de encontrar em Foucault aquele que reinstala no próprio âmago da história cultural ocidental essa figura como ausência, como falta em torno da qual se desdobram as epistemes a partir das quais pode surgir um olhar radicalmente novo sobre o passado da cultura ocidental e uma concepção mais lúcida de seu presente.

Para autores como Dosse (2007) e Revel (2015), essa compreensão epistemológica apresenta-se no pensamento de Merleau-Ponty, posto que ele se despede de certa maneira de compreender a Filosofia e a História, rejeitando a ideia de uma consciência nua ou de uma História como relato de fatos verdadeiros ou determinados: a História é, antes de tudo, angústia, aproximando-se intensamente de uma perspectiva subjetiva a esse respeito que, seguramente, influenciou o jovem Michel Foucault, seu futuro ouvinte, nas lições que proferiu na Sorbonne e no Collège de France (MERLEAU-PONTY, 1945). Em sua filosofia, MerleauPonty considera a vida tal como ela é construída no cotidiano, nos gestos e nas relações entre homens e mulheres. "É essa vida que se trata de tornar espaço do político, porque é ela 
que tece inelutavelmente a trama da história; e que nos pertence, a nós, vivos, para construir paisagens futuras" (REVEL, 2015, p. 143).

\section{PIONEIROS DOS ESTUDOS DO CORPO NA FRANÇA: ANOS 1970-1980}

Na França, nos anos 1970, a possibilidade de se fazer uma tese sobre o corpo, para alguém vindo de uma formação em Educação Física, encontra sua realização no domínio mais abrangente das Ciências da Educação, mais abertas a essa problemática que no domínio da Filosofia, notadamente graças a Georges Snyders e Guy Avanzini, exceção feita a Jacques Ulmann e Georges Canguilhem para a tese de Christian Pociello, defendida em 1974, e a de André Rauch, sob a orientação de Georges Gusdorf à Strasbourg (Quadro 1).

Quadro 1 - Teses sobre o corpo em Ciências Humanas e Sociais França (1970-1980)

Université Paris 5, 1981, André Rauch, "Le souci du corps : histoire d'un territoire pédagogique, 1740-1920". Dir Georges Snyders

Université Paris 8, 1980, Alex Lainé, "Les modèles du corps dans le discours dominant en éducation physique et sportive : leurs fondements épistémologique, axiologiques, leur portée éducative", Dir. Michel Lobrot.

Université Paris 7, 1978, Paul Corizon, "Les discours sur le corps en éducation physique 1945-1970", Dir. Claude Revault d'Allones.

Université Lyon 2, Arnaud, Pierre. Le Corps a sa raison ou de la finalité de l'éducation physique s.l. : s.n., 1978. - 527 f. en 2 vol ; $30 \mathrm{~cm}$ Th. 3è cycle : Lyon 2 : 1978, Dir Guy Avanzini.

Université Paris 8, 1978, Jacques Salzer, La place de l'expression corporelle dans la formation à la communication, Michel Lobrot (1924-)

Université Paris 5, 1977, Georges Vigarello (1941-) "Le corps redressé culture et pédagogie”, G. Snyders (directeur).

Université Paris 7, Marie-Martine Hommel-Ramanantsoa, Approche psychophysiologique du schéma corporel, Th. 3è cycle : Sc. de l'éduc., éduc. physique : Paris 7, Dir Jean Delacour

Université Paris 8, 1975, Claude Pujade-Renaud, Danse et narcissisme, Dir. Pierre Fédida

Université Paris 7, 1974, Christian Pociello, "Physiologie et éducation physique au XIXe siècle. J. E. Marey é G. Demeny Dir Georges Canguilhem".

Université de Strasbourg, 1967, André Rauch, Aspects d'une histoire du corps : D'Homère à Socrate, Thèse de Doctorat du 3eme cycle de la faculté de Lettres de Strasbourg, 258 p. Di. Georges Gusdorf

Fonte: <http:/corail.sudoc.abes.fr - Le catalogue du Système Universitaire de Documentation>. janvier 2017. Grifos nossos.

As condições de emergência do corpo no título das teses devem distinguir 0 reconhecimento oficial e a lenta introdução, talvez mesmo a legitimidade, do tema "corpo" como objeto de pesquisa e de titulação. Essa invenção teórica de novos sujeitos de tese sobre o corpo participa do movimento social de liberação dos costumes, mesmo que não seja realizada inteiramente pelos mesmos autores. Passamos a destacar alguns pioneiros desses estudos filosóficos e históricos do corpo na França, entre os anos 1960 e 1980, cujas obras abrem perspectivas ainda atuais para a Educação Física e STAPS, tais como André Rauch, Georges Vigarello e Michel Bernard, que serão tematizados neste ensaio. André Rauch é um dos pioneiros em Ciências das Atividades Físicas e Esportivas (STAPS), sendo o primeiro, em junho de 1967, a defender uma tese de filosofia sobre o corpo: 
filosófica'. Resta a elucidar em seguida o interesse pela noção de educação física. Ela é de ordem mais geral e concerne ao campo epistemológico das reflexões sobre o corpo e sua educação ou sua reeducação, no fim dos anos 50 e seguintes. Nesse período, o uso do termo 'educação física' encontra-se em concorrência com toda uma rede conceitual que introduz o termo 'psyché' (psíquico). Psicomotricidade, psicocinética, psicossomático, etc. Falar de 'physique' (físico) ou de 'educação física' parece fora de moda, deslocado mesmo, pois parece se limitar ao que é 'físico' na ação motriz, sem incluir o aspecto psicológico da conduta. É sem dúvida esse distanciamento que suscita a curiosidade dos pesquisadores e, sobretudo, dos historiadores. Estudar as origens do conceito, seu campo de aplicação, sua evolução permite colocar em perspectiva seu uso a partir da metade do século XVIII. Em um primeiro momento, ela [a educação física] aplica-se sobretudo à educação da criança no interior da família e das recomendações dirigidas pelos médicos as mães de família. Mais tarde, ela entra no campo dos pedagogos e educadores. Em Strasbourg, Georges Gusdorf introduziu o que ela chama de 'Antropologia filosófica' (...). A questão do corpo e de sua educação, em revanche, continuava no coração de minhas preocupações. Então eu me voltei para as ciências da educação, em direção a Georges Snyders (1917-2011), ele mesmo filósofo, para elaborar ou contribuir para uma história do conceito de educação física. Nós caminhamos então aproximadamente uma dezena de anos em direção ao que se chamará 'O cuidado do corpo' (RAUCH, 2011, ENTREVISTA)².

O autor enfatiza o processo de produção de sua tese, no qual a questão do corpo é compreendida na relação entre Filosofia e História. Tal abordagem é fecunda para a compreensão da corporeidade, das práticas corporais e suas representações, ideologias, imaginários. Em 1981, André Rauch defende sua tese de Estado ${ }^{3}$ na Universidade Paris 5, sobre "O Cuidado do corpo: história de um território pedagógico - 1740-1920". No artigo intitulado Entre le clos et l'ouvert, publicado na revista Esprit, em um número consagrado à Educação Física, ele precisa como a educação do corpo não pode reganhar a Educação Física como sendo seu "lugar de origem". Dado que as técnicas do gesto retêm do corpo somente a força, a flexibilidade e a postura: a exaltação heroicizada da juventude através do que seria a exploração esportiva favorece a emulação dessa retórica, "[...] constrangendo a educação física a habitar do lado da máquina, de um corpo submisso aos impulsos da emulação" (RAUCH, 1975, p. 678). Nesse contexto, convém não mais ligar a experiência do corpo somente a um saber técnico, pois "[...] tudo se passa como se o homem tivesse se tornado inapto para avaliar, ele mesmo, seu próprio corpo" (RAUCH, 1975, p. 684).

André Rauch retoma a distinção entre esporte amador e profissional na codificação da performance, em sua obra de 1982: Le corps en éducation physique. Para o autor a filosofia do esporte se traduz por signos (recordes, performances, premiações) e em uma aritmética do esforço como meio de produzir um modo de vida e de promover um ideal aristocrático para a juventude. $O$ sonho de realizar uma iniciação para a liberdade, através de uma reforma inglesa da vida escolar, parece se aperfeiçoar por "[...] virtudes morais de responsabilidade do indivíduo e por uma organização democrática" (RAUCH, 1982, p. 83). Nesse sentido, "[...] a cultura física ambiciona menos reforçar uma conduta industriosa e melhorar a rentabilidade que de ajustar seu uso a uma nova clientela" (RAUCH, 1982, p. 65).

No tocante à história do corpo, destacam-se os trabalhos de Georges Vigarello. Após sua agregação em Filosofia, em 1977, ele defende uma tese sob a direção de Georges Snyders

2 Entrevista não publicada com André Rauch feita pelo autor em 10 de outubro de 2011.

3 A Tese de Estado na França corresponde atualmente à Habilitação para dirigir pesquisas (HDR), feita posteriormente a tese doutoral. A de André Rauch intitula-se Le souci du corps : histoire d'un territoire pédagogique, 1740-1920. 
(1917-2011), intitulada Le corps redressé, culture et pédagogie. Ele obteve a menção honrosa da banca examinadora composta por Georges Snyders, Isambert Jamati, Michel Bernard, Georges Canguilhem, François Dagognet e Jacques Ulmann. Com essa tese ele opera um deslocamento da Filosofia, como André Rauch, no coração mesmo de uma história periodizada do corpo, à maneira de Michel Foucault.

A partir de 1978, Georges Vigarello abre um canteiro ligando pedagogia corporal, história do exercício físico e higienismo. Ele estuda a educação corporal através das técnicas para corrigir a postura. Assim, inventa uma via ainda pouco explorada, exceção feita a Robène (2006), qual seja: a história das técnicas através de uma análise que abrange o passado e os dias atuais das culturas esportivas. Como filósofo, ele interroga sobre as estruturas mitológicas do espetáculo esportivo, comparando o jogo antigo e o show midiático no sentido de um heroísmo da performance.

Em uma correspondência, Georges Vigarello comenta a respeito das questões teóricas de sua tese $e^{4}$ :

A primeira ideia referia-se à incontestável presença da cultura no que parecia ser eminentemente natural: a atitude física, por exemplo, na qual a retidão parece eterna ainda que seus detalhes, perfis, ideais e modalidades variam fortemente no tempo. Esse tema é fundamental e me parece ter sido aplicado aqui pela primeira vez, com essa forma em todo caso: os cambrés com os coletes e a teatralização das posturas clássicas ainda não haviam sido relacionados ao relaxamento com controle teorizado das posturas contemporâneas. Do mesmo modo o perfil físico do burguês não é o mesmo que o do nobre. 0 que revela, de passagem, o quanto prevalecem insensivelmente no mundo ocidental princípios de esbelteza e emagrecimento do corpo, tendo como horizonte a funcionalidade, a mobilidade e visando uma adaptação ao mundo das técnicas e fluxos, visando um 'domínio de si'; principio primeiro das sociedades 'democratizadas'. Esses temas serão aprofundados em seguida na história da beleza e da obesidade. Uma segunda ideia porta sobre as pedagogias: 0 tema da mão adulta. Eu tinha o sentimento que essa mão após ter sido aplicada fortemente sobre o corpo da criança para 'submetê-lo' (...). Um terceiro tema tratava das representações do corpo: as expectativas experimentadas em relação a um corpo 'concebido' como humoral e que são diferentes de um corpo 'concebido' como energético, mudando a visão dos exercícios, das eficiências, das avaliações e dos cálculos. Ora, esses modelos mudam com o tempo. Eu pressenti, começando o trabalho (Le corps redressé data dos anos 1970), que essa história poderia ser também uma história das representações globais dos funcionamentos corporais na história. E, de fato, eu apresentei uma sucessão de modelos (humoral, mecânico, energético, informacional, entre outros). Essa sucessão está no centro de meus trabalhos posteriores. Eu reivindico esse estudo como uma das originalidades de minha pesquisa (VIGARELLO, 2010, CORRESPONDÊNCIA).

Trata-se de fazer do corpo um objeto de saberes, em uma dada cultura e em um dado tempo, a partir de variadas fontes, textos e materialidades. Nessa entrevista, o autor também se refere a uma possível crítica vinda dos historiadores em geral: "Eles preferem prioritariamente os trabalhos centrados sobre um período preciso e limitado. Eu assumo essa perspectiva transhistórica e pluridisciplinar com total determinação. Eu a acho mesmo indispensável para fazer avançar os trabalhos históricos" (VIGARELLO, 2010, CORRESPONDÊNCIA).

Em maio de 1975, Vigarello dirige um número especial da revista Esprit, sobre Educação Física. Tal edição representa uma virada na história e filosofia do esporte. Ao

4 Correspondência não publicada entre o autor e Georges Vigarello, em 23 de junho de 2010. 
distinguir Educação Física e esporte, o autor precisa como a cultura em suas implicações corporais serve ao projeto para "[...] melhor viver o corpo na educação" (VIGARELLO, 1975, p. 641). No contexto ministerial da promoção do esporte, ele recusa reduzir a educação corporal a uma educação esportiva. A expressão corporal, a sociomotricidade, a psicomotricidade e as técnicas do gesto, como novas práticas, revelam a emergência de métodos e de experiências que se distanciam do instrumentalismo, da estetização e da colonização teórica do pensamento médico em um domínio da motricidade. As problemáticas novas colocam uma "[...] complexidade epistemológica" face às ciências, assim como conceitos inéditos (VIGARELLO, 1975, p. 643).

Nesse contexto de problemáticas inéditas no campo da Educação Física, destaca-se uma fenomenologia da expressão corporal, desenvolvida na França, inicialmente por Michel Bernard e Claude Pujade-Renaud. A influência de Michel Bernard (1927-2015) na ENSEPS é essencial e merece ser situada. Ele é o autor da obra pioneira Le corps, de 1972. Em seguida, em 1976, ele defendeu a tese, sob a orientação de Paul Ricœur sobre "a expressividade do corpo", que foi publicada sob o título L'expressivité du corps. Recherches sur les fondements de la théâtralité.

A fenomenologia da expressividade corporal descrita por Michel Bernard se separa do que ele estima ser a de Merleau-Ponty em sua "essência idealista", mesmo se sabemos que há uma ruptura entre a fenomenologia da percepção e os últimos textos de MerleauPonty para enfatizar a expressividade ${ }^{5}$, mas tal trajetória crítica não é abordada por Michel Bernard. No Livro Corps, ele não desenvolve uma filosofia do esporte, mas uma filosofia do corpo. Ele reconhece que toda abordagem do corpo implica uma escolha filosófica. Assim a "[...] filosofia não pode evitar ou evacuar uma reflexão sobre o corpo sem se condenar a ser apenas uma especulação vazia, fútil, estéril” (BERNARD, 1972, p. 8). Michel Bernard apresenta uma crítica à ambivalência do corpo nas Instruções Oficiais da Educação Física de 1967. Para ele, o vocabulário funcionalista do modelo tecnicista do corpo encontra, no sistema neuromuscular voluntário, modos de redução do esforço. Assim, o ajustamento do corpo ao mundo encontra no modelo econômico do capitalismo analisado por Marx os modos de rendimento que caucionariam o controle do corpo e melhoria de qualidades psicológicas (BERNARD, 1975). Nesse momento da Educação Física, Michel Bernard lamenta que o corpo do qual trata a Educação Física seja "[...] um corpo deserotizado, dessexualizado e mesmo assexuado" (BERNARD 1975, p. 734). Face a essa crítica, a filosofia da expressividade do corpo continua a influenciar estudos no campo das artes e da própria Educação Física.

Essas referências têm contribuído para o desenvolvimento da pesquisa em STAPS, notadamente com um viés mais próximo do olhar da filosofia e da história do corpo, abrindo perspectivas para a interface, os intercâmbios e o debate epistemológico na França e no Brasil, em especial no que concerne ao trabalho de Georges Vigarello, bastante traduzido em língua portuguesa.

\section{PIONEIROS DOS ESTUDOS DO CORPO NO BRASIL: ANOS 1970-1990}

Nesta parte do ensaio, apresentamos de forma não exaustiva alguns pioneiros dos estudos do corpo na Educação Física brasileira (Quadro 2), tendo como pano de fundo a relação entre a história e a filosofia do corpo; bem como as perspectivas de formação acadêmica, projetos de pesquisa, publicações e parcerias entre pesquisadores brasileiros e franceses. 
Nesse contexto, destacamos as produções de Silvino Santin e de Carmen Soares como sendo representativas de nosso escopo de pesquisa. Nota-se ainda que os autores brasileiros aqui citados também são influenciados pelos pioneiros dos estudos do corpo franceses, posto que o pensamento de Merleau-Ponty irá influenciar a obra de Silvino Santin; bem como Michel Foucault e Georges Vigarello são referências para a pesquisa elaborada por Carmen Soares em sua trajetória. O movimento do pensamento de ambos os autores em ambos os países marcará as obras publicadas e a formação de professores e pesquisadores no campo da Educação Física no Brasil e na França, configurando referências epistemológicas cujas ressonâncias se cruzam, dialogam e reverberam em problemáticas e reflexões pertinentes e atuais.

Quadro 2 - Teses sobre Corpo, Esporte e Educação Física: Brasil (1970-1990)

Université Paris IV (Paris-Sorbonne), França. Silvino Santin. Être et Langage chez Maurice Merleau-Ponty, 1974. Orientador: Emmanuel Lévinas.

Gottfried Wilhelm Leibniz Universität Hannover, LUH, Alemanha. Elenor Kunz. Veränderungsperspektive zum Brasilianischen Schulsport, 1987. Orientador: Andreas Heinrich Trebels.

Carl von Ossietzky Universität Oldenburg, UNI/Oldenburg, Alemanha. Valter Bracht. Sport und Politik in Brasilien 1990. Orientador: Bero Rigauer.

Universidade Estadual de Campinas, UNICAMP, Brasil. Wagner Wey Moreira. Educação Física Escolar: Uma Abordagem Fenomenológica, 1990. Orientador: Sérgio Goldenberg.

Université Paris Diderot, PARIS 7, França. Denise Sant'Anna. La recherche de la beauté, 1994. Orientador: Michelle Perrot.

Universidade Estadual de Campinas, UNICAMP, Brasil. Carmen Lucia Soares. Imagens da Educação no Corpo: estudo a partir da ginástica francesa no século XIX, 1996. Orientador: Milton José de Almeida.

Fonte: CNPq- Plataforma Lattes, acesso em 6 de janeiro de 2017

Em 1974, Silvino Santin defende sua tese de doutorado na Sorbonne, sob a direção de Emmanuel Levinas, intitulada "Être et langage chez Maurice Merleau-Ponty", para a qual obteve uma bolsa do Governo Francês. Sua tese porta sobre a linguagem como abertura do ser no mundo. Na esteira de Merleau-Ponty, ele afirma que a linguagem não é mais uma vestimenta do pensamento. Trata-se de uma "[...] reflexão liberada de sua bagagem cultural, vendo e escutando as perspectivas da verdade que se escondem e se desvelam em cada virada da história e em cada manifestação do ser" (SANTIN, 1974, p. 18). Nota-se o cruzamento entre Filosofia e História para interrogar o ser na relação com a consciência perceptiva do eu e do outro, a produção da significação e o caminho da expressão no qual se destacam o corpo e as emoções, o gesto e a palavra. Esses temas da tese serão desdobrados pelo autor em suas publicações.

As contribuições de Silvino Santin para os estudos do corpo, em particular na Educação Física, são inúmeras e não poderiam aqui ser todas recenseadas. Dentre elas, destacamos o livro Educação Física: uma abordagem filosófica da Corporeidade, publicado em 1987 e que permanece atual, em particular no que concerne a uma introdução à noção de corporeidade no campo da Educação Física. Essa discussão da corporeidade na Educação Física brasileira, em particular em sua abordagem fenomenológica, encontrará espaço na obra de outros estudiosos, tais como Wagner Wey Moreira e Elenor Kunz, como bem demonstram os estudos de Almeida, Bracht e Ghidetti (2013).

O trabalho de Santin é pioneiro, posto que dá visibilidade no campo da Educação Física a essa temática, também em relação aos estudos franceses, em particular a fenomenologia, 
na qual o autor foi formado diretamente. Ademais, o livro Educação Física: uma abordagem filosófica da Corporeidade é o primeiro no Brasil a abordar a temática, sendo composto por artigos apresentados pelo autor em vários eventos, cuja discussão se volta para a crítica ao dualismo corpo e mente, em prol da ludicidade e da sensibilidade estética.

"No princípio, quando a Educação Física precisava mostrar sua identidade, os debates pedagógicos, sociológicos, psicológicos, filosóficos, políticos eram acalorados" diz Santin em autobiografia publicada na revista Motrivivência (SANTIN, 2010, p. 412). Para o autor não se trata de seguir a história da filosofia, mas indagar sobre a sua inserção na realidade da Educação Física, sua relação com o corpo, o esporte, o lazer, o movimento humano. Santin (1987) reflete a respeito dos aspectos intencionais do movimento humano - influência de sua formação fenomenológica, delimitando os componentes intencionais do movimento em internos e externos. Os internos são: expressividade, competitividade, prazer, premiação, produtividade. Os externos são os troféus, os resultados, o bem-estar, o rendimento, o lazer, etc.

No artigo "Perspectivas na visão de corporeidade", afirma o conhecimento do corpo a partir do próprio corpo e das experiências corporais, reafirmando a tese fenomenológica capaz de fazer frente a uma "corporeidade disciplinada" (SANTIN, 1992). Com base na literatura fenomenológica, Santin $(1974 ; 1987 ; 1992)$ afirmará que o homem é um ser que se move, que brinca e que sente. Esses aspectos estão presentes em seu pensamento a respeito da Educação Física e do esporte e continuam atuais para a produção de conhecimento na área, inclusive para repensar suas práticas pedagógicas, de lazer, de performance com base nos princípios fenomenológicos da corporeidade, do lúdico e da estética (aisthesis) compreendida como sensibilidade, estando, portanto, ligada ao corpo, às emoções e aos afetos.

Outra referência emblemática de nosso estudo encontra-se na obra de Carmen Soares a respeito da História da Educação Física e do corpo no Brasil, em fecundo diálogo com as fontes francesas. Soares $(1994 ; 1998 ; 2001 ; 2007 ; 2011 ; 2016)$ tem aprofundado a história da Educação Física brasileira a partir da "educação do corpo":

Vivemos na civilização da novidade, do rejuvenescimento, da cirurgia plástica. 0 corpo suscita infindáveis possibilidades de estudo. Ele é a primeira forma de visibilidade humana. De forma aguda, nos obriga a pensar na vida, mas também na morte; no prazer, mas também na dor; no humano e no desumano que encarnam as aparências; nas tiranias da aparência (SOARES, 2001 b, p. 16).

Soares (2001 a; 2007; 2016) abre um profícuo diálogo com pesquisadores brasileiros e franceses que estudam o corpo na Educação Física por meio de abordagens históricas e filosóficas:

É na década de 1980, mais ao seu final, no Brasil, que as ciências humanas, a educação e as artes passam a dar fundamento para a pesquisa em educação física, fenômeno que ocorre em consequência de um certo número de pesquisadores da educação física que opta por fazer sua formação de pós-graduação em história, sociologia, antropologia, filosofia, educação, arte. Ainda minoritários no campo, esses pesquisadores vêm contribuindo de maneira significativa para a ampliação de temas, objetos e interpretações das manifestações próprias ao campo da educação física e ao mesmo tempo estabelecendo parcerias importantes como sociólogos, filósofos e historiadores, agregando o olhar de dentro da área a esses campos (SOARES, 2007, p. viii).

Sua tese de doutorado, publicada no livro Imagens da educação no corpo: estudo a partir da ginástica francesa no século XIX, traz nas primeiras páginas uma citação da tese 
de Georges Vigarello, já mencionada neste ensaio, sobre o corpo como o primeiro lugar da educação. Fazemos esse destaque para nuançar nossa tese da transversalidade dos estudos do corpo, as parcerias entre História e Filosofia no Brasil e na França, sendo a obra de Carmen Soares exemplar dessa compreensão.

A obra de Carmen Soares é marcada por um estilo de escrita que conduz o leitor a instalar-se em uma temporalidade que permite compreender diferentes lógicas e processos; bem como os sentidos da duração que se constroem também no corpo. Baseada no pensamento de Georges Vigarello e colaboradores, a autora afirma que "[...] na longa duração, as representações do corpo também testemunham a materialidade informada por atos de conhecimento" (SOARES; TERRA, 2007, p. 102).

A referência ao pensamento de Michel Foucault também constitui um traço marcante do trabalho da autora para refletir sobre as pedagogias do corpo, o esporte, a higiene: "O que seriam as ginásticas e o esporte senão pedagogias higiênicas, táticas sempre atualizadas e ressignificadas de investimento no corpo, na intimidade de sua fisiologia, na gestão de seus desejos?" (SOARES, 2006, p. 75).

Em seus mais recentes livros, a autora alarga esses horizontes a partir de suas análises sobre "um estilo de vida esportivo", uma "moda esportiva" (SOARES, 2011); bem como os estudos sobre "uma educação pela natureza" em que continua as parcerias com pesquisadores franceses e brasileiros, como Jacques Gleyse (GLEYSE; SOARES; DALBEN, 2014; GLEYSE, 1997; 2010) e Bernard Andrieu (ANDRIEU, 2016), ambos situados no campo da história e da filosofia do corpo. Para a autora, a natureza que educa é aquela desenhada pela cidade, sobretudo produzida pela aliança estabelecida entre médicos e educadores, transformando-se num campo de saber cuja extensão de conselhos almeja se estender ao conjunto da população (MEDEIROS; SOARES, 2017).

\section{CONSIDERAÇÕES FINAIS}

Os exemplos apresentados remetem à transversalidade da problemática do corpo nas pesquisas em Educação Física e em STAPS no Brasil e na França, dando visibilidade às conexões, diálogos e parcerias estabelecidas. Trata-se de uma abordagem que se situa entre a história das ideias, a história cultural e a Filosofia como estratégias teóricas e metodológicas que investem na pesquisa sobre o corpo e que têm contribuído para a formação acadêmica e profissional na Educação Física e Ciências do Esporte em geral.

Os objetos, os conceitos, as estratégias metodológicas colocam em pauta um olhar transversal sobre o corpo constituído como objeto de pesquisa e sobre o qual repousam histórias sociais, individuais e coletivas ao longo do tempo e que também são transformadas pelas culturas, normatizações, resistências. Como nos mostra Vigarello (2016), a respeito da percepção do corpo e da composição de uma sensibilidade contemporânea, "[...] o corpo diz 0 sentimento direto de suas transformações" (VIGARELLO, 2016, p. 49).

A partir desse prisma, novas agendas de pesquisa se abrem, se interrogam, dialogam. Nas obras desses autores, observa-se uma Filosofia que ultrapassa o cartesianismo e que recusa esposar "uma consciência nua", para tanto, une-se à História para compreender as aventuras e angústias da aventura humana na longa duração, nos espaços íntimos e sociais, notadamente no domínio dos estudos do corpo e da corporeidade. Outros autores franceses 
e brasileiros se inscrevem nesse contexto de diálogo entre história e filosofia do corpo e que merecem estudos específicos a serem feitos posteriormente como forma de contribuir para 0 debate epistemológico na área, ampliando-se parcerias, diálogos, estratégias de pesquisa e referenciais teóricos.

\section{REFERÊNCIAS}

ALMEIDA, Felipe; BRACHT, Valter; GHIDETTI, Filipe. A presença da fenomenologia na educação física brasileira: implicações para o estudo do corpo e outras problematizações. Educación Física y Ciencia, v. 15, n. 2, p.1-16, 2013.

ANDRIEU, Bernard. Le corps dispersé: Une histoire du corps au XXe siècle. Paris : L'harmattan, 1993.

ANDRIEU, Bernard. A la recherche du corps: Epistémologie de la recherche française en Sciences Humaines et Sociales. Nancy: Universitaire de Nancy, 2005.

ANDRIEU, Bernard. A osmose solar: colorir a sua pele ou mergulhar no calor? In: SOARES, Carmen (Org.). Pesquisas sobre o corpo: ciências humanas e educação. Campinas: Autores Associados, 2007. p. 263- 279.

BERNARD, Michel. Le corps, Paris: Delarge, 1972.

BERNARD, Michel. L'expressivité du corps. Paris: Delarge, 1976.

BRUAIRE, Claude. Philosophie du corps. Paris: Seuil, 1968.

CORBIN, Alain. COURTINE, Jean-Jacques; VIGARELLO, Georges (Éds). Histoire du corps. Paris : Seuil, 2006. v.3.

COURTINE, Jean-Jacques. (Éd.). Histoire du corps. Les mutations du regard : Le XXe siècle. Paris: Seuil, 2006.

DOSSE, François. História do estruturalismo. São Paulo: EDUSC, 2007. v.1.

FOUCAULT, Michel. As palavras e as coisas. São Paulo: Martins Fontes, 1992.

GLEYSE, Jacques. L'instrumentalisation du corps: Une archéologie de la rationalisation instrumentale du corps, de l'Âge classique à l'époque hypermoderne. Paris: L'Harmattan, 1997.

GLEYSE, Jacques. Le verbe et la chair : un siècle de bréviaires de la République Une archéologie du corps dans les manuels scolaires français de morale et d'hygiène (1880-1974). Paris: L'Harmattan, 2010.

GLEYSE, Jacques; SOARES, Carmen. Os manuais escolares franceses de educação física, de higiene e de moral seriam sexistas? (1880-2004). Educação e Sociedade, v.29, n.102, p. 137156, 2008.

GLEYSE, Jacques; SOARES, Carmen. Como se fabricam os anjos? Uma arqueologia do corpo nos manuais escolares de moral e de higiene na França, 1880-1974. Revista Brasileira de Ciências Esporte, v.34, n. 4, p. 805- 824, 2012. 
GLEYSE, Jacques; SOARES, Carmen; DALBEN, André. L'œuvre de Georges Hébert au Brésil et en France dans les écrits sur l'Education physique. Deux facettes de la nature (1909-1957) ? Sport History Review, v. 45, p. 171-199, 2014.

MEDEIROS, Daniele; SOARES, Carmen. Uma natureza que educa: as estâncias hidrominerais no Estado de São Paulo (1930-1940). Movimento, v. 23, n. 3, p. 949-962, 2017.

MENDES, Isabel; GLEYSE, Jacques. O cuidado de si em Michel Foucault: reflexões para a Educação Física. Movimento, v. 21, n.2, p. 507-520, 2015.

MERLEAU-PONTY, Maurice. La Guerre a eu lieu. Revue Les Temps Moderns, n.1. p. 48-66, 1945.

MERLEAU-PONTY, Maurice. Signes. Paris: Gallimard, 1960.

NÓBREGA, Terezinha Petrucia et al. Educação Física e epistemologia: a produção do conhecimento nos congressos brasileiros de ciências do esporte. Revista Brasileira de Ciências do Esporte, v. 24, n. 2, p.173-185, 2003.

NÓBREGA, Terezinha Petrucia; MENDES, Isabel; GLEYSE, Jacques. Compreensões de corpo na educação física: análise de conteúdo das revistas EPS (França) e RBCE (Brasil). Revista Brasileira de Ciências do Esporte. v 38, n.3, p. 227-234, 2016.

RAUCH, André. Entre le clos et l'ouvert. Revue Esprit, n.5, p. 672-686, 1975.

RAUCH, André. Le corps en éducation physique: histoire et principe de l'entraînement. Paris: PUF, 1982.

RAUCH, André. Le souci du corps: histoire de l'hygiène en éducation physique. Paris : PUF, 1983.

REVEL, Judith. Foucault avec Merleau-Ponty: ontologie politique, présentisme et histoire. Paris: Vrin, 2015.

ROBÈNE, Luc. L'homme en mouvement. Histoire et anthropologie des techniques sportives: Techniques sportives et société. Paris: Chiron, 2006. v.1.

SAINT-AUBERT, Emmanuel. Être et chair I. Du corps au désir : l'habilitation ontologique de la chair, Paris : Vrin, 2013.

SANTIN, Silvino. Être et langage chez Maurice Merleau-Ponty. 1974. 314f. Thèse (Troisième cycle em Philosophie) - Université Paris 4 Sorbonne. Paris, 1974.

SANTIN, Silvino. Educação Física: uma abordagem filosófica da corporeidade. ljuí: UNIJUÍ, 1987.

SANTIN, Silvino. Perspectivas na visão de corporeidade. In: MOREIRA, W. W. (Org.) Educação Física e esportes: perspectivas para o século XXI. Campinas: Papirus, 1992. p. 51-69.

SANTIN, Silvino. Silvino Santin por ele mesmo: um currículo não acadêmico. Motrivivência, v.21, n. 32/33, p. 410-412, 2010.

SOARES, Carmen. Educação Física: Raízes europeias e Brasil. Campinas: Autores Associados, 1994.

SOARES, Carmen. Imagens da educação no corpo: estudo a partir da ginástica francesa no século XIX. Campinas: Autores Associados, 1998. 
SOARES, Carmen (Org.). Corpo e história: Campinas: Autores Associados, 2001 a.

SOARES, Carmen (Org.). Pesquisas sobre o corpo: ciências humanas e educação. Campinas: Autores Associados, 2007.

SOARES, Carmen; TERRA, Vinicius. Lições de anatomia: geografias do olhar. In: SOARES, Carmen. (Org.). Pesquisas sobre o corpo: ciências humanas e educação. Campinas: Autores Associados, 2007.p. 101-116.

SOARES, Carmen. Pedagogias do corpo: higiene, ginásticas, esporte. In: RAGO, Margareth; VEIGA-NETO, Alfredo. Figuras de Foucault. Belo Horizonte: Autêntica, 2006. p. 75-85.

SOARES, Carmen. Entrevista. JORNAL DA UNICAMP, v.15, n.161, abr. 2001 b. Disponível em: $<$ https://www.unicamp.br/unicamp/unicamp hoje/ju/abril2001/pag16abril2001.htm> Acesso em: 7 jan. 2017.

SOARES, Carmen. As roupas nas práticas corporais e esportivas: a educação do corpo entre o conforto, a elegância e a eficiência (1920-1940). Campinas: Autores Associados, 2011.

SOARES, Carmen (Org.). Uma educação pela natureza: a vida ao ar livre, o corpo e a ordem urbana. Campinas: Autores Associados, 2016.

VIGARELLO, GEORGES. Le corps redressé: histoire d'un pouvoir pédagogique. Paris: Delarge, 1978.

VIGARELLO, Georges. Le sentiment de soi : Histoire de la perception du corps XVle - XXe siècle. Paris: Seuil, 2016. 
